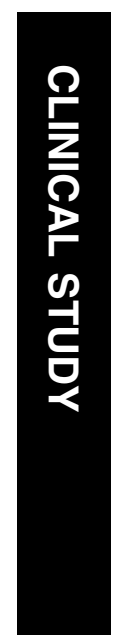

\title{
Prevalence of pinguecula and pterygium in a general population in Spain
}

${ }^{1}$ Department of

Ophthalmology, Complexo Hospitalario de Pontevedra, Pontevedra, Spain

${ }^{2}$ Clinical Epidemiology Unit, Hospital Clínico Universitario de Santiago, Santiago de Compostela, Spain

${ }^{3}$ Instituto de Investigaciones Sanitarias de Santiago, Santiago de Compostela, Spain

\section{${ }^{4}$ Department of} Ophthalmology, Hospital Clínico Universitario de Santiago, Santiago de Compostela, Spain

\section{${ }^{5}$ Department of} Ophthalmology, University of Santiago de Compostela, Santiago de Compostela, Spain

Correspondence: E Viso, Department of Ophthalmology, Complexo Hospitalario de Pontevedra, 36003 Pontevedra, Spain Tel: + 3498684 8084; Fax: + 34986807078 . E-mail: evo@mundo-r.com

Received: 16 April 2010 Accepted in revised form: 11 November 2010 Published online: 24 December 2010

\begin{abstract}
Purpose To determine the prevalence of pinguecula and pterygium and to investigate their associations in a general adult population in North-Western Spain. Methods An age-stratified random sample of 1155 subjects $\geq 40$ years was selected in O Salnés (Spain). From 937 eligible subjects, $619(66.1 \%)$ participated (mean age (SD): 63.4 (14.5) years, range: $40-96$ years, $37.0 \%$ males). An interview to collect history of systemic diseases and lifestyle details and a comprehensive ophthalmic evaluation in which pinguecula and pterygium were recorded was carried out. The prevalence of pinguecula and pterygium and their relationship with lifestyle factors and ocular and systemic diseases was investigated. Results The prevalence of pinguecula was 47.9\% (95\% confidence interval (CI): 43.9-51.9). This prevalence increased significantly with aging $(P=0.002)$ and was higher in men (56.4\%; 95\% CI: $50.0-62.7)$ than in women (42.7\%; 95\% CI: $37.8-47.8)(P=0.001)$. The prevalence of pterygium was $5.9 \%$ (95\% CI: 4.3-7.9). This prevalence also increased significantly with aging $(P=0.005)$ and was $4.8 \%(95 \% \mathrm{CI}: 2.6-8.4)$ in men and 6.5\% (95\% CI: $4.5-9.3)$ in women $(P=0.346)$. After controlling for age and sex, pinguecula was associated with alcohol intake (adjusted odds ratio $\left(\mathrm{OR}_{\mathrm{a}}\right)$ : 3.08 ; 95\% CI: 1.60-5.95), pterygium with fluorescein staining $\left(\mathrm{OR}_{\mathrm{a}}: 2.64\right.$; 95\% CI: 1.08-6.46) and both disorders with outer activity $\left(\mathrm{OR}_{\mathrm{a}}: 2.07 ; 95 \%\right.$ CI: $1.36-3.15$ and 2.28; 95\% CI: 1.04-4.98, respectively). Conclusions Pinguecula is far more common than pterygium. Alcohol consumption is strongly associated with pinguecula. Fluorescein staining is highly prevalent in subjects with pterygium. Both disorders
\end{abstract}

E Viso', F Gude ${ }^{2,3}$ and MT Rodríguez-Ares A $^{4,5}$

increase with age and are associated with outer activity.

Eye (2011) 25, 350-357; doi:10.1038/eye.2010.204; published online 24 December 2010

Keywords: pinguecula; population-based; prevalence; pterygium; Spain

\section{Introduction}

Pinguecula and pterygium are disorders of the conjunctiva of unknown aetiology that can cause ocular irritation, visual disturbances, and a cosmetic effect that is usually the main concern of the patients. They can also generate frustration in the affected individuals because there is no medical treatment available and surgical removal, which is indicated in some cases of pterygium, is often ineffective. ${ }^{1}$

The few population-based studies on the prevalence of pinguecula that have been conducted to date show estimate rates $>50 \%$ in the adult population. ${ }^{2-4}$ The prevalence of pterygium in this kind of studies shows geographical and ethnic variation ranging from 0.7 to $>30 \%$, with higher rates in general in regions where sun radiation is most intense as around the equator ${ }^{5-8}$ or at high altitudes, ${ }^{9,10}$ and in darker skin individuals. ${ }^{6,11}$ However, although advances have been made in the knowledge of the distribution and associations of pinguecula and pterygium, there are large areas such as Southern Europe where the prevalence of these diseases has not been sufficiently investigated. Furthermore, the factors responsible for the variation observed among studies performed in similar latitudes remain elusive.

The Salnés Eye Study was designed to provide population-based epidemiological information of ocular diseases in the population older than 40 years living in O Salnés, Spain. 
In previous reports, we described the prevalence and associations of dry eye and pseudoexfoliation. ${ }^{12,13}$ In this paper, we examine the prevalence of pinguecula and pterygium and its relationship with systemic and ocular diseases and lifestyle factors.

\section{Materials and methods}

\section{Study design and setting}

This cross-sectional study was performed in O Salnés area (42 degrees north of the equator), in North-Western Spain. This maritime area covers an area of $170 \mathrm{~km}^{2}$ and had a total population of 72500 of whom 33649 were older than 40 years in 2005, when the study began. The climate in this location is rainy and temperate with mean annual rainfall of up to $16001 / \mathrm{m}^{2}$.

\section{Participants}

An aged-stratified random sample of the population $\geq 40$ years $(n=1155)$ was drawn from the National Health Service Registry, which covers $>95 \%$ of the population. The sample was stratified in age groups as follows: 40-49 years, 50-59 years, 60-69 years, 70-79 years, and $\geq 80$ years. A computer program generated a random sample of equal numbers $(n=225)$ of subjects in each age group, except for the last group ( $\geq 80$ years), which was oversampled because of an expected lower response rate $(n=255)$. These 1155 individuals were invited to participate in the study by a personal letter. From this initial sample, those unable to give informed consent were considered ineligible to participate in the study. This included patients with mental or severe organic diseases $(n=75)$, people who for several reasons could not be contacted or no longer lived in the area $(n=104)$ and those who had died before they were called for the examination $(n=39)$. From the remaining eligible 937, a total of 619 subjects, all of them Spanish

Caucasians, agreed to participate (overall participation rate was $66.1 \%$ ). Mean age (SD) of the sample studied was 63.4 (14.5) years (range: 40-96 years). Two hundred and twenty-nine were males $(37.0 \%)$ and three hundred and ninety were females $(63.0 \%)$. Fishing and agriculture were prevalent activities, representing $84.4 \%$ of total outer occupations. There were no significant differences in age or gender between subjects who agreed to participate in the study and those who did not. The study profile is summarized in Figure 1. A detailed description has been published elsewhere. ${ }^{12}$

\section{Data collection}

From May 2005 to March 2006, all subjects were successively convened for evaluation. A structured questionnaire was administered by trained physicians. It included (a) basic demographic data; (b) predominantly indoor or outdoor occupational activity; (c) educational level, in four categories of studies: none, elementary (6-11 years), secondary (12-18 years), and university; (d) alcohol consumption and smoking; and (e) dry eye questionnaire. Occupational activity was evaluated on the basis of average daytime sun exposure experienced. Occupations such as fisherman or construction worker, which involved at least half of the

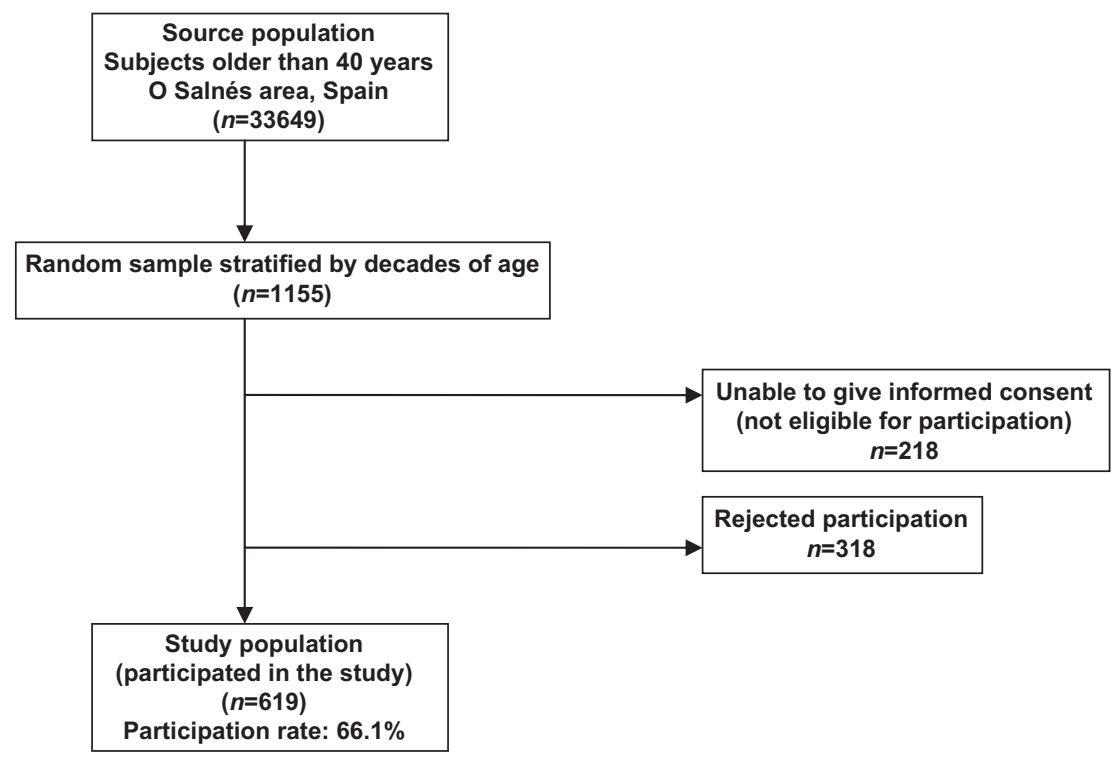

Figure 1 Study profile. 
time spent outdoors, were considered outdoor occupational activities, whereas occupations such as factory worker or government officer, which involved less than half of the time outdoors, were considered indoor occupational activities.

Alcohol intake was registered in each subject by adding up the total number of standard drinking units (one bottle of beer, one glass of wine, or one unit of spirit, all of them approximately equivalent to $10 \mathrm{~g}$ of ethanol) habitually consumed per week. Subjects were classified according to alcohol intake into three groups as follows: (a) abstainers, (b) light drinkers (consumers of 1 to 14 units/week), and (c) heavy drinkers (consumers of $>14$ units a week). Subjects were classified according to smoking habit into three groups as follows:

(a) non-smokers, (b) ex-smokers (a person who had smoked regularly in the past and had quit smoking $\geq 1$ year before the date of the interview), and (c) current smokers (a person who smokes any tobacco product either daily or occasionally). A questionnaire, which had previously been used by Schein et al, ${ }^{14}$ was used to evaluate dry eye symptoms. Subjects were considered symptomatic when at least one (out of six) of the symptoms of the questionnaire was experienced often or all the time (Table 1).

A comprehensive medical history including medication use was collected with special attention to common systemic disorders such as diabetes or hypertension and disorders associated with ocular surface disease such as rosacea and allergy. A subject was considered to have diabetes if he or she had been diagnosed by a physician, was treated with insulin or oral hypoglycaemic agents. Study participants were deemed to have hypertension, rosacea, or allergy if they reported being told by a physician that they had those diseases.

A slit lamp was used to examine the anterior segment for evidence of pinguecula or pterygium. The diagnosis of pinguecula was made when the typical yellowish lesion that forms on the nasal or temporal conjunctiva was present. Pterygium was diagnosed if the characteristic interpalpebral radially orientated fibrovascular lesion crossing the corneoscleral limbus was present or if pterygium surgery had been carried out.

Table 1 Dry eye questionnaire

1. Do your eyes ever feel dry?

2. Do you ever feel a gritty or sandy sensation in your eyes?

3. Do your eyes ever have a burning sensation?

4. Are your eyes ever red?

5. Do you notice much crusting on your lashes?

6. Do your eyelids ever get stuck?

Possible answers were 'never', 'rarely', 'sometimes', 'often', or 'all the time'.
A thorough examination of the eyelid margins, meibomian glands, conjunctiva, and cornea was then carried out. Absent, viscous, or waxy white secretion upon digital expression, lid margin telangiectasia, or plugging of the meibomian gland orifices was considered evidence of meibomian gland dysfunction. Tear breakup time (TBUT) and fluorescein staining were performed following the instillation of one drop of sodium fluorescein $1 \%$ in the lower conjunctival sac. The tear film was observed with a slit lamp with a cobalt-blue filter after asking the patient to blink several times. The time, in seconds, between the last blink and the first desiccation spot was recorded. The mean of three of these recordings, taken after one single instillation of a drop of fluorescein, was registered as the tear film breakup time. Fluorescein staining of the cornea, which was measured after the first reading of TBUT, was graded as 0 (no staining); 1 (mild staining, limited to $<1 / 3$ of the corneal surface); 2 (moderate staining, between 1 and 3); and 3 (severe staining, occupying half or more of the corneal surface). TBUT $\leq 10 \mathrm{~s}$ and fluorescein staining score $\geq 1$ were considered positive.

Other anterior segment variables that were recorded included the presence of pseudoexfoliative material on the anterior capsule or in the pupil margin, and iris colour, which was classified as light (blue, green), medium (mixture of brown, green, and yellow), and dark (brown, black).

The Schirmer test was performed in both eyes. Five minutes following the instillation of one drop of oxybuprocaine hydrochloride $0.4 \%$ the inferior fornix was gently blotted and a precalibrated standard filter strip was placed in the lower temporal fornix, which remained for $5 \mathrm{~min}$. During this time, the participants were instructed to look slightly upwards and blink normally. After removing the strip, the length of the wetting was measured. The test result was considered positive if this measurement was $\leq 5 \mathrm{~mm}$.

A dilated non-contact biomicroscopic examination of the fundus with $\mathrm{a}+78 \mathrm{D}$ lens was also performed to detect signs of age-related macular degeneration. Age-related macular degeneration was determined and classified according to the Wisconsin age-related macular degeneration grading system. ${ }^{15} \mathrm{~A}$ retina specialist confirmed these diagnoses.

The examinations were performed in two sessions, which took place at two different dates. The first session included the interviewer administered questionnaire and the Schirmer test. The second session included the systematic biomicroscopic examination and the dilated fundus evaluation. The analyses were conducted on the basis of a person, not per eye. All the examinations were carried out by an experienced ophthalmologist, at the same place, and with the same instrumentation. 


\section{Ethical considerations}

Informed written consent was obtained from all participants. The study conformed to the principles of the Helsinki 1975 declaration, and was reviewed and approved by the Regional Research Committee.

\section{Statistical analysis}

In order to account for the stratified sampling, a designbased analysis was performed. The sampling procedures used in the study departed from unequal probability selection. Compensatory weights were developed to obtain estimates (prevalence and odds ratios (ORs), with their corresponding 95\% confidence intervals (CIs)) from the original target population in the study area. To account for weighting and the sampling design, the STATA 7.0 (Stata Corp., College Station, TX, USA) statistical package was employed. To examine which factors were associated with pinguecula or pterygium, logistic regression analyses controlling for age and sex were performed. Age (years) entered the equation as a quantitative variable. The remaining variables were categorical (binary) and entered the equation as ' 1 ' (present or yes) or ' 0 ' (absent or no). Interactions terms were also assessed. Two-tailed $P$-values $<0.05$ were considered statistically significant.

\section{Results}

There were 298 persons with either unilateral $(n=33$ $(11.1 \%))$ or bilateral $(n=265(88.9 \%))$ pinguecula, equivalent to a weighted prevalence of $47.9 \%(95 \%$ CI: 43.9-51.9) in the population aged $\geq 40$ years. This prevalence increased significantly with age $(P=0.002)$ and was higher in men $(56.4 \%$; 95\% CI: 50.0-62.7) than in women $(42.7 \%$; 95\% CI: 37.8-47.8) $(P=0.001)$. There were 42 persons with either unilateral $(n=28(66.6 \%))$ or bilateral $(n=14(33.3 \%))$ pterygium, equivalent to a weighted prevalence of $5.9 \%$ (95\% CI: 4.3-7.9), which also increased with age $(P=0.005)$ and was $4.8 \%(95 \% \mathrm{CI}$ : 2.6-8.4) in men and 6.5\% (95\% CI: 4.5-9.3) in women $(P=0.346)$ (Table 2).

The age- and sex-adjusted ORs for the association of pinguecula and pterygium with lifestyle factors, ocular factors, and systemic diseases are presented in Table 3. Higher educational level was protective for pinguecula (OR $\mathrm{a}: 0.16$; 95\% CI: 0.06-0.38). Heavy (OR $\mathrm{a}: 3.08$; 95\% CI: 1.60-5.95) and also moderate alcohol intake $\left(\mathrm{OR}_{\mathrm{a}}: 1.95\right.$; 95\% CI: 1.37-2.78) were associated with pinguecula but not with pterygium. Both pinguecula and pterygium were associated with outer occupational activity $\left(\mathrm{OR}_{\mathrm{a}}\right.$ : 2.07; 95\% CI: 1.36-3.15 and OR $\mathrm{a}: 2.28$; 95\% CI: 1.04-4.98, respectively) and this association remained statistically
Table 2 Prevalence ${ }^{\mathrm{a}}$ of pinguecula and pterygium by age and sex

\begin{tabular}{|c|c|c|c|c|c|}
\hline & \multirow[t]{2}{*}{ At risk } & \multicolumn{2}{|r|}{ Pinguecula } & \multicolumn{2}{|r|}{ Pterygium } \\
\hline & & No & Prevalence & No & Prevalence \\
\hline Women & 390 & 167 & $42.7(37.8-47.8)$ & 30 & $6.5(4.5-9.3)$ \\
\hline \multicolumn{6}{|c|}{ Age groups (years) } \\
\hline $40-49$ & 79 & 30 & $36.1(26.5-47.0)$ & 3 & $3.6(1.8-10.6)$ \\
\hline $50-59$ & 81 & 32 & $41.0(30.7-52.2)$ & 3 & $3.8(1.2-11.3)$ \\
\hline $60-69$ & 78 & 41 & $52.6(41.5-63.3)$ & 7 & $8.9(4.3-17.6)$ \\
\hline 70-79 & 79 & 38 & $48.1(37.4-59.0)$ & 4 & $5.1(2.0-12.7)$ \\
\hline$\geq 80$ & 73 & 26 & $\begin{array}{c}35.1(25.2-46.5) \\
P=0.126\end{array}$ & 13 & $\begin{array}{c}17.6(10.5-27.9) \\
P=0.018\end{array}$ \\
\hline Men & 229 & 131 & $56.4(50.0-62.7)$ & 12 & $4.8(2.6-8.4)$ \\
\hline \multicolumn{6}{|c|}{ Age groups (years) } \\
\hline $40-49$ & 54 & 21 & $41.2(28.5-55.1)$ & 2 & $3.9(1.0-14.5)$ \\
\hline $50-59$ & 52 & 33 & $60.0(46.6-72.1)$ & 2 & $3.7(1.0-13.7)$ \\
\hline $60-69$ & 45 & 26 & $57.8(43.0-71.2)$ & 2 & $4.4(1.1-16.2)$ \\
\hline 70-79 & 45 & 36 & $79.5(65.0-89.0)$ & 2 & $4.5(1.1-16.6)$ \\
\hline \multirow[t]{2}{*}{$\geq 80$} & 33 & 15 & $46.9(30.5-64.0)$ & 4 & $12.5(4.7-29.0)$ \\
\hline & & & $P=0.003$ & & $P=0.594$ \\
\hline Both genders & 619 & 298 & $47.9(43.9-51.9)$ & 42 & $5.9(4.3-7.9)$ \\
\hline \multicolumn{6}{|c|}{ Age groups (years) } \\
\hline $40-49$ & 133 & 51 & $38.1(30.2-46.5)$ & 5 & $3.7(1.6-8.6)$ \\
\hline $50-59$ & 133 & 65 & $48.9(40.5-57.3)$ & 5 & $3.8(1.6-8.8)$ \\
\hline $60-69$ & 123 & 67 & $54.5(45.6-63.0)$ & 9 & $7.3(3.9-13.4)$ \\
\hline 70-79 & 124 & 74 & $59.7(50.9-67.9)$ & 6 & $4.8(2.2-10.3)$ \\
\hline \multirow[t]{2}{*}{$\geq 80$} & 106 & 41 & $38.7(30.1-48.2)$ & 17 & $16.0(10.2-24.2)$ \\
\hline & & & $P=0.002$ & & $P=0.005$ \\
\hline
\end{tabular}

Figures are number of subjects in each age group, number of affected subjects and prevalence values in percentages, with 95\% confidence intervals within parentheses.

${ }^{a}$ Weighted values.

significant after adjusting for other potential confounding variables such as alcohol intake, tobacco consumption, or educational level.

No association was found with dry eye symptoms or signs, except for fluorescein staining that was associated with pterygium $\left(\mathrm{OR}_{\mathrm{a}}\right.$ : 2.64; 95\% CI: 1.08-6.46), or with other ocular disorders such as pseudoexfoliation syndrome or meibomian gland dysfunction. No association was found with systemic diseases such as diabetes or allergy. Other factors that were examined but were not associated with the occurrence of pinguecula or pterygium included tobacco consumption and iris colour. Interaction terms were not statistically significant.

\section{Discussion}

In this study, pinguecula was detected in $47.9 \%$ and pterygium in $5.9 \%$ of the population aged $\geq 40$ years. The high proportion of persons with pinguecula is not a distinctive characteristic of this population as similar rates have been reported in areas as distant as Greenland 
Table 3 Factors associated with pinguecula and pterygium

\begin{tabular}{|c|c|c|c|c|c|c|}
\hline & \multicolumn{3}{|c|}{ Pinguecula } & \multicolumn{3}{|c|}{ Pterygium } \\
\hline & No & Yes & $O R_{a}$ & No & Yes & $O R_{a}$ \\
\hline \multicolumn{7}{|l|}{ Age groups (years) } \\
\hline $40-49$ & $82(61.7)$ & $51(38.3)$ & Ref & $128(96.2)$ & $5(3.8)$ & Ref \\
\hline $50-59$ & $68(51.1)$ & $65(48.9)$ & $1.54(0.94-2.52)$ & $128(96.2)$ & $5(3.8)$ & $1.02(0.29-3.62)$ \\
\hline $60-69$ & $56(45.5)$ & $67(54.5)$ & $1.99(1.20-3.31)$ & $114(92.7)$ & $9(7.3)$ & $2.03(0.66-6.21)$ \\
\hline $70-79$ & $50(40.3)$ & $74(59.7)$ & $2.48(1.50-4.08)$ & $118(95.2)$ & $6(4.8)$ & $1.31(0.39-4.38)$ \\
\hline$\geq 80$ & $65(61.3)$ & $41(38.7)$ & $1.08(0.63-1.83)$ & $89(84.0)$ & $17(16.0)$ & $4.83(1.73-13.5)$ \\
\hline \multicolumn{7}{|l|}{ Gender } \\
\hline Female & $224(57.4)$ & 166 (42.6) & Ref & $362(92.3)$ & $30(7.7)$ & Ref \\
\hline Male & $98(42.8)$ & $131(57.2)$ & $1.78(1.27-2.49)$ & $215(94.7)$ & $12(5.3)$ & $0.74(0.36-1.52)$ \\
\hline \multicolumn{7}{|l|}{ Educational level } \\
\hline None & $98(44.5)$ & $122(55.5)$ & Ref & $196(88.7)$ & $25(11.3)$ & Ref \\
\hline Elementary & $110(52.1)$ & $101(47.9)$ & $0.66(0.44-1.01)$ & $198(94.3)$ & $12(5.7)$ & $0.68(0.33-1.39)$ \\
\hline Secondary & $81(55.1)$ & $66(44.9)$ & $0.57(0.33-0.99)$ & $142(96.6)$ & $5(3.4)$ & $0.56(0.20-1.54)$ \\
\hline University & $33(80.5)$ & $8(19.5)$ & $0.16(0.06-0.38)$ & $41(100)$ & 0 & NA \\
\hline \multicolumn{7}{|l|}{ Alcohol intake } \\
\hline Abstainers & $181(62.0)$ & $111(38.0)$ & Ref & $272(93.2)$ & $20(6.8)$ & Ref \\
\hline 1-14 units/week & $123(46.2)$ & $146(54.8)$ & $1.95(1.37-2.78)$ & $248(92.5)$ & $20(7.5)$ & $0.88(0.45-1.72)$ \\
\hline$>14$ units/week & $18(31.0)$ & $40(69.0)$ & $3.08(1.60-5.95)$ & $56(96.6)$ & $2(3.4)$ & $0.65(0.13-3.19)$ \\
\hline \multicolumn{7}{|l|}{ Smoking habits } \\
\hline Non-smokers & $226(53.8)$ & $194(46.2)$ & Ref & $390(92.6)$ & $31(7.4)$ & Ref \\
\hline Ex-smokers & $48(42.1)$ & $66(57.9)$ & $1.21(0.74-1.98)$ & $106(93.8)$ & $7(6.2)$ & $1.46(0.55-3.89)$ \\
\hline Smokers & $47(55.3)$ & $38(44.7)$ & $0.89(0.52-1.52)$ & 81 (95.3) & $4(4.7)$ & $1.68(0.56-5.01)$ \\
\hline \multicolumn{7}{|l|}{ Profession } \\
\hline Indoors & $265(55.7)$ & $211(44.3)$ & Ref & $448(94.3)$ & $27(5.7)$ & Ref \\
\hline Outdoors & 48 (36.6) & $83(63.3)$ & $2.07(1.36-3.15)$ & $116(88.5)$ & 15 (11.5) & $2.28(1.04-4.98)$ \\
\hline \multicolumn{7}{|l|}{ Iris colour } \\
\hline Dark & $243(52.5)$ & $220(47.5)$ & Ref & $429(92.7)$ & $34(7.3)$ & Ref \\
\hline Medium & 47 (51.1) & 45 (48.9) & $1.07(0.68-1.69)$ & $85(92.4)$ & $7(7.6)$ & $0.94(0.40-2.25)$ \\
\hline Light & $31(48.4)$ & $33(51.6)$ & $1.19(0.68-2.07)$ & $61(95.3)$ & $3(4.7)$ & $0.28(0.04-2.08)$ \\
\hline \multicolumn{7}{|l|}{ DE symptoms } \\
\hline No DE symptoms & $257(52.0)$ & $238(48.0)$ & Ref & $463(93.5)$ & $32(6.5)$ & Ref \\
\hline DE symptoms & $64(51.6)$ & $60(48.4)$ & $1.03(0.83-1.27)$ & $114(50.9)$ & $110(49.1)$ & $1.08(0.50-2.31)$ \\
\hline \multicolumn{7}{|l|}{ Schirmer $\leq 5$} \\
\hline No Schirmer $\leq 5$ & $191(49.6)$ & $194(50.4)$ & Ref & $363(94.3)$ & $22(5.7)$ & Ref \\
\hline Schirmer $\leq 5$ & $131(56.2)$ & $102(43.8)$ & $0.78(0.55-1.09)$ & $212(91.4)$ & $20(8.6)$ & $1.50(0.77-2.89)$ \\
\hline \multicolumn{7}{|l|}{$T B U T \leq 10$} \\
\hline No TBUT $\leq 10$ & $268(51.3)$ & 254 (48.6) & Ref & 488 (93.7) & $33(6.3)$ & Ref \\
\hline $\mathrm{TBUT} \leq 10$ & $54(55.7)$ & $43(44.3)$ & $0.87(0.55-1.36)$ & $88(90.7)$ & $9(9.3)$ & $1.32(0.60-2.89)$ \\
\hline \multicolumn{7}{|l|}{$F \geq 1$} \\
\hline No $F \geq 1$ & $302(52.7)$ & $271(47.3)$ & Ref & 537 (93.9) & $35(6.1)$ & Ref \\
\hline $\mathrm{F} \geq 1$ & $20(43.5)$ & $26(56.5)$ & $1.53(0.78-2.98)$ & $39(84.8)$ & 7 (15.2) & $2.64(1.08-6.46)$ \\
\hline \multicolumn{7}{|l|}{$M G D$} \\
\hline No MGD & 215 (51.7) & $201(48.3)$ & Ref & $389(93.7)$ & $26(6.3)$ & Ref \\
\hline MGD & $106(52.5)$ & $96(47.5)$ & $0.90(0.62-1.29)$ & $186(92.1)$ & $16(7.9)$ & $0.84(0.43-1.64)$ \\
\hline \multicolumn{7}{|l|}{ Pseudoexfoliation } \\
\hline No PSX & $292(51.8)$ & $272(48.2)$ & Ref & $527(93.4)$ & $37(6.6)$ & Ref \\
\hline PSX & $29(52.7)$ & $26(47.3)$ & $0.75(0.40-1.39)$ & $50(90.9)$ & $5(9.1)$ & $0.95(0.33-2.67)$ \\
\hline
\end{tabular}


Table 3 (Continued)

\begin{tabular}{|c|c|c|c|c|c|c|}
\hline & \multicolumn{3}{|c|}{ Pinguecula } & \multicolumn{3}{|c|}{ Pterygium } \\
\hline & No & Yes & $O R_{a}$ & No & Yes & $O R_{a}$ \\
\hline \multicolumn{7}{|l|}{$A R M D$} \\
\hline No ARMD & $302(51.7)$ & $282(48.3)$ & Ref & 545 (93.5) & $38(6.5)$ & Ref \\
\hline ARMD & $14(50.0)$ & $14(50.0)$ & $0.89(0.40-1.96)$ & $25(89.3)$ & $3(10.7)$ & $1.05(0.30-3.66)$ \\
\hline \multicolumn{7}{|l|}{ Rosacea } \\
\hline No rosacea & $306(51.3)$ & $291(48.7)$ & Ref & 557 (93.3) & $40(6.7)$ & Ref \\
\hline Rosacea & $15(68.2)$ & 7 (31.8) & $0.52(0.21-1.31)$ & $20(90.9)$ & $2(9.1)$ & $1.09(0.25-4.77)$ \\
\hline \multicolumn{7}{|l|}{ Allergy } \\
\hline No Allergy & $304(51.7)$ & $284(48.3)$ & Ref & $548(93.2)$ & $40(6.8)$ & Ref \\
\hline Allergy & 17 (54.8) & $14(45.2)$ & $1.10(0.51-2.36)$ & $29(93.5)$ & $2(6.5)$ & $1.76(0.38-8.07)$ \\
\hline \multicolumn{7}{|l|}{ Diabetes } \\
\hline No Diabetes & $280(52.7)$ & $251(47.3)$ & Ref & 499 (94.0) & $32(6.0)$ & Ref \\
\hline Diabetes & $41(46.6)$ & $47(53.4)$ & $1.30(0.81-2.09)$ & 78 (88.6) & 10 (11.4) & $1.43(0.66-3.08)$ \\
\hline
\end{tabular}

Abbreviations: ARMD, age-related macular degeneration; $\mathrm{DE}$, dry eye; NA, not available; $\mathrm{OR}_{\mathrm{a}}$, age- and sex-adjusted odds ratio with $95 \%$ confidence intervals within parentheses; Ref, reference value; TBUT, tear film breakup time.

Values represent number of subjects with row percentages within parentheses.

Interaction terms were not statistically significant.

Italic entries indicate associations that are statistically significant.

Table 4 Prevalence of pinguecula and pterygium in population-based studies

\begin{tabular}{|c|c|c|c|c|c|c|c|}
\hline \multirow[t]{2}{*}{ Study } & \multirow[t]{2}{*}{ Country } & \multirow[t]{2}{*}{ Sample (n) } & \multirow[t]{2}{*}{ Age (years) } & \multicolumn{2}{|c|}{ Prevalence (\%) } & \multicolumn{2}{|c|}{ Association } \\
\hline & & & & Pinguecula & Pterygium & Age & Sex \\
\hline \multirow[t]{2}{*}{ Norm $^{2}$ (1979) } & Greenland & 659 & & 56.0 & 8.6 & $S$ & NS \\
\hline & Denmark & 810 & & 41.0 & 0.7 & S & NS \\
\hline Panchapakesan $e t a l^{3}$ & Australia & 3564 & $\geq 49$ & 69.5 & 7.3 & $S$ & Men \\
\hline McCarty et $a l^{16}$ & Australia & 5147 & $40-101$ & - & 2.8 & S & Men \\
\hline Luthra et $a l^{11}$ & Barbados & 2617 & $40-84$ & - & 23.4 & S & NS \\
\hline Wong et $a l^{24}$ & China & 1232 & $40-79$ & - & 6.9 & S & Men \\
\hline Gazzard et $a l^{27}$ & Indonesia & 403 & $\geq 40$ & - & 16.8 & S & NS \\
\hline Paula et $a l^{5}$ & Brazil & 624 & Adults & - & 18.4 & NS & NS \\
\hline Lu et $a l^{10}$ & China & 2229 & $\geq 40$ & - & 14.5 & $S$ & Women \\
\hline Ma et $a l^{17}$ & China & 4439 & $\geq 40$ & - & 2.9 & $S$ & Men \\
\hline Durkin et $a l^{6}$ & Myanmar & 2076 & $\geq 40$ & - & 19.6 & S & NS \\
\hline West and Munoz ${ }^{26}$ & USA (latinos) & 4767 & $\geq 40$ & - & 16.2 & NS & Men \\
\hline Shimora et $a l^{7}$ & Japan & 3762 & $\geq 40$ & - & 30.8 & $S$ & Men \\
\hline This study (2010) & Spain & 619 & $40-96$ & 47.9 & 5.9 & $\mathrm{~S}$ & $\mathrm{NS}^{\mathrm{a}}$ \\
\hline
\end{tabular}

Abbreviations: NS, not significant; S, significant.

apinguecula is associated with male sex.

or Australia, where more than a half of the adult individuals were found to have pinguecula. ${ }^{2,3}$ A $22.5 \%$ rate has also been reported recently ${ }^{4}$ but methodological factors such as the study design or age range of the participants probably explain the lower prevalence estimate found in this investigation.

The proportion of pterygium is more difficult to compare because of the variation in pterygium prevalence observed among different populations
(Table 4), with higher rates in general in regions close to the equator and at high altitudes. Paula et $a l^{5}$ reported a $18.4 \%$ rate in an equatorial area in Brazil and Lu et al ${ }^{9}$ a $17.9 \%$ rate in a Mongolian population in an area where the average altitude was $3450 \mathrm{~m}$ in contrast to the $2.8 \%$ prevalence estimate reported in Australia ${ }^{16}$ or the $2.9 \%$ rate found in China, ${ }^{17}$ areas situated outside the so-called pterygium belt ${ }^{18}$ (located between 37 degrees north and south of the equator). Ultraviolet radiation, which is 
considered the cause of this geographical association, would eventually lead to the formation of pterygium through mechanisms that include the production of p53, ${ }^{19,20}$ certain proinflammatory cytokines, ${ }^{21}$ and matrix metalloproteases. ${ }^{22}$ Higher rates are also observed in darker skin individuals as shown in the Barbados Eye Study in which $23.4 \%$ of the black participants had pterygium, a frequency that more than doubled the frequency of $10.2 \%$ among whites. ${ }^{11}$ However, some studies cannot be explained on geographical or ethnic grounds, which suggests that not only variable methodologies but also unidentified genetic or environmental factors other than geographical location and ethnicity may have a role in the pathogenesis of pterygium.

In this study, outer occupational activity was associated both with pinguecula and pterygium and this association remained significant after adjusting for potential confounding variables. The considerable number of people involved in fishing and agriculture in this area, which are some of the outer activities that most increase the cumulative exposure to ultraviolet $B$ radiation, could explain the higher prevalence of pterygium in this study (5.9\%) compared with the prevalence observed in Australia (2.8\%) and in other investigations performed in Caucasians living in areas with similar climate. ${ }^{16}$ Other lifestyle factors associated with the semirural character of this population that predispose people to spend more time outdoors might also be important. It must be noted at this point that the absence of reliable methods to measure sunlight exposure hinders comparisons among studies.

Furthermore, protective mechanisms (use of hats and sunglasses) to reduce the amount of light reaching the eye, which have been found in some studies to greatly influence the prevalence of this disease, ${ }^{10,11}$ were not evaluated.

Alcohol use had a significant effect on the prevalence of pinguecula but not on the prevalence of pterygium. The increased oxidative stress that results from alcohol use might favour the development of the degenerative changes associated with pinguecula but not the proliferative process that occurs in pterygium. The lack of association between alcohol consumption and pterygium is consistent with the few studies that have evaluated the prevalence of alcohol consumption and risk of pterygium. ${ }^{23}$ We cannot compare our findings with respect to the association between alcohol consumption and pinguecula with other populationbased studies as virtually none have evaluated this relationship.

Stratification of random sampling by decades of age offered a broad view of time course changes. Both disorders increased with age in agreement with previous population-based studies. The prevalence of pinguecula stabilized after the age of 60 years in women and after the age of 70 years in men in contrast to the prevalence of pterygium that was highest in persons aged $\geq 80$ years. Men were at a higher risk of developing pinguecula. This association between pinguecula and the male sex must not be explained by a selection bias in men participation, as the low proportion of men in the sample derives not only from a true difference in gender distribution in the population of reference but also from the non-proportional sampling method used in this study, with the same number of subjects in each stratum. The association between pterygium and sex is controversial. In this study, pterygium was not associated with either sex. However, some studies report that men are at higher risk of developing pterygium than women, ${ }^{7,16,24-26}$ and others, although fewer in number, ${ }^{10}$ do the opposite.

The apparent protective association of higher level of education on the development of pinguecula was probably due to confounding since higher educational level is associated with more qualified jobs, which are likely to require less time spent outdoors than jobs with a lower degree of specialization. Similarly, an association was found between fluorescein staining and pterygium but, in contrast with other studies, ${ }^{28}$ not with symptoms or with other signs of dry eye despite the fact that chronic inflammation has been postulated as a contributing factor for the development of pterygium. Meibomian gland dysfunction was also examined but no significant association was found with this ocular surface disorder either.

The main strength of this study is the populationbased approach, which enables to obtain a representative sample of the population. However, the $33.9 \%$ of the eligible subjects who did not participate was a source of potential selection bias. To evaluate the possibility of this bias, gender and age were compared between subjects who participated and those who did not. The similar proportions found in this evaluation confirmed the representative character of the sample (data not shown). The examination of all the subjects by a single ophthalmologist was also a limitation of the study because, although it minimizes interobserver error, it prevents reproducibility assessments.

In summary, in this population-based study, nearly half of the population had pinguecula, which was more frequent in men. The prevalence of pterygium was higher than in other Caucasian populations with similar climate. Both disorders increased with age and were strongly associated with sunlight exposure. The association found between pinguecula and alcohol consumption needs further investigation. 


\section{Summary}

\section{What was known before}

- The prevalence of pinguecula appears to be as high as $50 \%$ in the few population-based studies that have been performed. The prevalence of pterygium shows geographical and ethnic variation ranging from 0.7 to $>30 \%$. Ultraviolet $\mathrm{B}$ radiation seems to be the most important factor for the development of these disorders.

What this study adds

- This study adds new data on the prevalence of pinguecula and pterygium as it is the first population-based investigation on the prevalence of these disorders in Spain. It confirms the association with age and outer occupational activity. The association between pinguecula and alcohol consumption is a novel finding.

\section{Conflict of interest}

The authors declare no conflict of interest.

\section{Acknowledgements}

This study was supported by grants from the Xunta de Galicia (PGIDIT05SAN52PR) and the Fondo de Investigaciones Sanitarias (RD06/0018/0006). F Gude was supported by a grant (BAE09/90052) from the Carlos III Health Institute (Spanish Ministry of Science and Technology).

\section{References}

1 Alpay A, Ugurbas SH, Erdogan B. Comparing techniques for pterygium surgery. Clin Ophthalmol 2009; 3: 69-74.

2 Norm MS. Prevalence of pinguecula in Greenland and in Copenhagen, and its relation to pterygium and spheroid degeneration. Acta Ophthalmol 1979; 57: 96-105.

3 Panchapakesan J, Hourihan F, Mitchell P. Prevalence of pterygium and pinguecula: The Blue Mountains Eye Study. Aust NZ J Ophthalmol 1998; 26: 2-5.

4 Fotouhi A, Hashemi H, Khabazkhoob M, Mohammad K. Prevalence and risk factors of pterygium and pinguecula: The Tehran Eye Study. Eye 2009; 23: 1125-1129.

5 Paula JS, Thorn F, Cruz AA. Prevalence of pterygium and cataract in indigenous populations of the Brazilian Amazon rain forest. Eye 2006; 20: 533-536.

6 Durkin SR, Abhary S, Newland HS, Selva D, Aung T, Casson RJ. The prevalence, severity and risk factors for pterygium in central Myanmar: The Meiktila Eye Study. Br J Ophthalmol 2008; 92: 25-29.

7 Shiroma H, Higa A, Sawaguchi S, Iwase A, Tomidokoro A, Amano $S$ et al. Prevalence and risk factors of pterygium in a South-western island of Japan: The Kumejima Study. Am J Ophthalmol 2009; 148: 766-771.

8 Cajucom-Uy H, Tong L, Wong TY, Tay WT, Saw SM. The prevalence of and risk factors for pterygium in an urban Malay population: The Singapore Malay Eye Study. Br J Ophthalmol 2010; 94: 977-981.
9 Lu J, Wang Z, Lu P, Chen X, Zhang W, Shi K et al. Pterygium in an aged Mongolian population: a population-based study in China. Eye 2009; 23: 421-427.

10 Lu P, Chen X, Kang Y, Ke L, Wei X, Zhang W. Pterygium in Tibetans: a population-based study in China. Clin Experiment Ophthalmol 2007; 35: 828-833.

11 Luthra R, Nemesure BB, Wu SY, Xie SH, Leske MC. Frequency and risk factors for pterygium in the Barbados Eye Study. Arch Ophthalmol 2001; 119: 1827-1832.

12 Viso E, Rodríguez-Ares MT, Gude F. Prevalence of and associated factors for dry eye in a Spanish adult population (The Salnés Eye Study). Ophthalmic Epidemiol 2009; 16: 15-21.

13 Viso E, Rodríguez-Ares MT, Gude F. Prevalence of peudoexfoliation syndrome in Spanish adults in the Salnés Eye Study. Ophthalmic Epidemiol 2010; 17: 118-124.

14 Schein OD, Muñoz B, Tielsch JM, Bandeen Roche K, West S. Prevalence of dry eye among the elderly. Am J Ophthalmol 1997; 124: 723-728.

15 Klein R, Davis MD, Magli YL, Segal P, Klein BE, Hubbard L. The Wisconsin age related maculopathy grading system. Ophthalmology 1991; 98: 1128-1134.

16 McCarty CA, Fu CL, Taylor HR. Epidemiology of pterygium in Victoria, Australia. Br J Ophthalmol 2000; 84: 289-292.

$17 \mathrm{Ma} \mathrm{K}, \mathrm{Xu} \mathrm{L}$, Jie Y, Jonas JB. Prevalence of and factors associated with pterygium in adult Chinese (The Beijing Eye Study). Cornea 2007; 26: 1184-1186.

18 Cameron ME. Pterygium Throughout the World. Charles C. Thomas: Springfield, IL, 1965.

19 Tan DT, Lim AS, Goh HS, Smith DR. Abnormal expression of the p53 tumor suppressor gene in conjunctiva of patients with pterygium. Am J Ophthalmol 1997; 123: 404-405.

20 Dushku N, Reid TW. P53 expression in altered limbal basal cell of pingueculae, pterygia and limbal tumors. Curr Eye Res 1997; 16: 1179-1192.

21 Kria L, Ohira A, Amemiya T. Immunohistochemical localization of basic fibroblast growth factor, platelet derived growth factor, transforming growth factor-beta and tumor necrosis factor-alpha in the pterygium. Acta Histochem 1996; 98: 195-201.

22 Li DQ, Lee SB, Gunja-Smith Z, Liu Y, Solomon A, Meller D et al. Overexpression of collagenase (MMP-1) and stromelysin (MMP-3) by pterygium head fibroblasts. Arch Ophthalmol 2001; 119: 71-80.

$23 \mathrm{Xu} \mathrm{L}$, You QS, Jonas JB. Prevalence of alcohol consumption and risk of ocular diseases in a general population: The Beijing Eye Study. Ophthalmology 2009; 116: 1872-1879.

24 Wong TY, Foster PJ, Johnson GJ, Seah SK, Tan DT. The prevalence and risk factors for pterygium in an adult Chinese population in Singapore: The Tanjong Pagar Survey. Am J Ophthalmol 2001; 131: 176-183.

25 Tan CSH, Lim TH, Koh WP, Liew GC, Hoh ST, Tan CC et al. Epidemiology of pterygium on a tropical island in the Riau Archipelago. Eye 2006; 20: 908-912.

26 West S, Munoz B. Prevalence of pterygium in latinos: proyecto VER. Br J Ophthalmol 2009; 93: 1287-1290.

27 Gazzard G, Saw SM, Farook M, Koh D, Widjaja D, Chia SE et al. Pterygium in Indonesia: prevalence, severity and risk factors. Br J Ophthalmol 2002; 86: 1341-1346.

28 Lu P, Chen X, Liu X, Yu L, Kang Y, Xie Q et al. Dry eye syndrome in elderly Tibetans at high altitude. A populationbased study in China. Cornea 2008; 5: 545-551. 